\title{
Numerical analysis of natural convection and entropy generation in a 3D partitioned cavity
}

\author{
Olfa Yejjer ${ }^{1}$, Lioua Kolsi ${ }^{1,2 *}$, Abdullah A.A.A. Al-Rashed ${ }^{3}$, Abdelkarim Aydi $^{4}$, Mohamed N. \\ Borjini $^{1}$, Habib Ben Aissia ${ }^{1}$ \\ ${ }^{1}$ Unité de Métrologie et des Systèmes Énergétiques, École Nationale d’Ingénieurs, University of \\ Monastir, Monastir 5000, Tunisia \\ ${ }^{2}$ College of Engineering, Mechanical Engineering Department, Haïl University, Haïl 2240, Saudi \\ Arabia \\ ${ }^{3}$ Dept. of Automotive and Marine Engineering Technology, College of Technological Studies, The \\ Public Authority for Applied Education and Training, 86250, Kuwait \\ ${ }^{4}$ Department of Chemical and Materials Engineering, College of Engineering, Northern Border \\ University, Arar 1321, Saudi Arabia \\ Email: lioua_enim@yahoo.fr
}

\begin{abstract}
The effect of inclination angle on three dimensional (3D) natural convection in an inclined rectangular cavity similar to a solar collector equipped with partitions has been investigated numerically. Governing equations were established using the 3D velocity vector-vorticity formalism and discretized via the finite volume method (FVM). A parametric study has been performed for various inclination angles (from $0^{\circ}$ to $90^{\circ}$ ), different partitions length (from 0.2 to 0.8 ), and a range of Rayleigh numbers varied from $10^{3}$ to $10^{5}$ while, Prandtl number was fixed at $\operatorname{Pr}=0.71$. Results are reported in terms of iso-surfaces of temperature, isotherms, particles trajectories, vector velocity projection, average Nusselt number and the entropies generation contours and graphs. Results showed the 3D character of the flow is more pronounced for higher Rayleigh numbers and lower partition lengths. For all inclinations and partition lengths, heat transfer and entropy generation are enhanced by increasing Rayleigh number
\end{abstract}

Keywords: 3D, Entropy Generation, Inclination Angles, Natural Convection, Partitions.

\section{INTRODUCTION}

Natural convection in differentially heated inclined cavities was the subject of an important number of researches. To study the effect of this inclination on heat transfer and fluid flow, authors choose different ranges of angles. Hinojosa et al. [1] numerically simulated, for a range of ten angles between $0^{\circ}$ and $180^{\circ}$, the variation of the Nusselt numbers with inclination for different Rayleigh numbers in a tilted cubic cavity. Sharma [2], gave a critical angle corresponding to a maximum average Nusselt number at same geometry. Kolsi [3] studied the three-dimensional inclined solar distiller with a moving cold wall to investigate the double diffusive natural convection and the entropy generation at different Reynolds numbers and inclination angles. A two-dimensional investigation was made by Aminossadati and Ghasemi [4] on a square cavity showing that the inclination effect on heat transfer, is more important at high Rayleigh numbers. The same configuration has been studied by Abu-Nada and Oztop [5] for Copper-water nanofluid filled cavity. Heat transfer enhances by the addition of nanoparticles and decreases with the inclination angle. Oztop et al. [6] considered an open porous tilted square and concluded that the inclination angle is the most important control parameter for the evolution of the flow and the convection. Kherief et al. [7] considered an inclined rectangular cavity filled with mercury in the presence of a magnetic field which reduce significantly the average Nusselt number, as well as Hussein et al. [8] who's considered a range of angles between $0^{\circ}$ and $90^{\circ}$ to study the magnetohydrodynamic natural convection in an inclined trapezoidal enclosure filled with a fluid-saturated porous medium. Some authors have chosen to add partitions in different position on the cavities; for example, Mamou et al. [9] studied the heat transfer for different inclinations and partition's number and thickness. Hussain et al. [10] studied the effect of the length and location of one partition attached in the bottom of a particular cavity having an adjacent inclined single cold wall and gave the variations of the Nusselt number with different conditions of wall inclinations and partitions locations. BenNakhi and Chamkha [11] put in evidence the effect of the inclination angles and the partition lengths on the natural convective heat transfer and the fluid flow inside an inclined enclosure equipped with partitions; they predict an average 
Nusselt number decreasing with the increase of the inclination angle beyond $30^{\circ}$, and show that the average Nusselt number increases with Rayleigh numbers and the flow speed decreases with the increase of the partitions length.

In addition to the natural convection and fluid flow, some researches treated the effect of inclination on entropy generation. Irreversibilities are mainly due to heat transfer and fluid friction [12-27]. For an inclined rectangular cavity, Bouabid et al. [28] analyzed the influence of different parameters on the behavior of the entropy production for a transient regime and concluded that the entropy increases with the inclination angles for a fixed aspect ratio and Grashof number and reaches its maximum, depending on the aspect ratio, then decrease and get same value at the limits angles $0^{\circ}$ and $180^{\circ}$. In the same way, Baytas [29] identified some optimum angles for which the energy lost is minimum in an inclined square cavity. In fact, for small Rayleigh number values, the entropy production decreases with the inclination. Shavik [30] showed that the entropy generation, in an inclined square, increases with the inclination at the high Rayleigh numbers whereas Bouabid et al. [31] introduced, for a similar cavity, a magnetic field and showed that it decreases the entropy generation.

In continuation with what was previously dealt in literature, this work corresponds to a study of the inclination angles effect with an interest to more parameters like the partitions length. This parameter was studied by several researchers like Amraqui et al. [32] and Ben-Nakhi and Chamkha [11], but the most important study has been made by Heidary [33] who combined the study of the inclination effect of the partitioned cavity with the effect of the length and location of partitions on the heat transfer, fluid flow and entropy generation. The study is made numerically on twodimensions. So the aim of the present work is to investigate the natural convection and entropy production in a threedimensional inclined and partitioned rectangular cavity. This geometry can be assimilated to a solar collector. The temperature field, flow structure and entropy generations are evaluated for different inclinations and the partitions length.

\section{GEOMETRY AND MATHEMATICAL MODEL}

The three-dimensional studied geometry is an inclined parallelepiped equipped by five partitions as shown in (Fig. $1)$. It is an inclined rectangular cavity with a variable inclination angle $\alpha$. The length of the partitions $L_{p}$ is also variable. $\mathrm{L}_{\mathrm{x}}, \mathrm{L}_{\mathrm{y}}, \mathrm{L}_{\mathrm{z}}$ present consecutively the depth, the width, and the length of the cavity; the thickness e of the partitions and the distance $\mathrm{d}$ between theme are fixed.

The two horizontal walls representing the glazing of the collector (upper face) and the absorber (lower face), are maintained at hot $\left(\mathrm{T}_{\mathrm{h}}\right)$ and cold $\left(\mathrm{T}_{\mathrm{c}}\right)$ temperature respectively, while the lateral walls are maintained adiabatic. To develop the mathematical model, some simplifying assumptions were presented; the fluid is Newtonian, incompressible and the flow is laminar, the heat transfer by radiation is neglected; the specific heats $C_{p}$ and the viscosity $v$ are assumed constant and the Boussinesq approximation were adopted.

In order to eliminate the pressure gradient terms, the numerical method used to solve the governing equations in this work is based on "the vector potential-vorticity " $(\vec{\psi}-\vec{\omega})$ Formalism ".

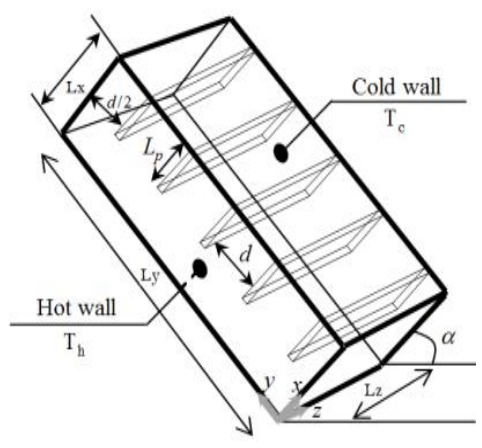

Figure 1. Geometry of the problem under consideration

$\vec{u}^{\prime}=\vec{\nabla} \times \vec{\psi}^{\prime}$ and $\vec{\omega}^{\prime}=\vec{\nabla} \times \vec{u}^{\prime}$

The continuity, momentum and energy equations are as following:

$\nabla \cdot \vec{V}^{\prime}=0$

$\rho\left(\frac{\partial \vec{V}^{\prime}}{\partial t^{\prime}}+(\vec{V} \cdot \vec{\nabla}) \cdot \vec{V}^{\prime}\right)=\mu \Delta \vec{V}^{\prime}-\nabla \vec{P}^{\prime}+\beta\left(T^{\prime}-T_{0}\right) \vec{g}$

$\frac{\partial T^{\prime}}{\partial t^{\prime}}+\left(T^{\prime} \cdot \vec{\nabla}\right) \cdot T^{\prime}=\alpha \Delta T^{\prime}$

The dimensionless equations are established using the following expressions:

$t=\frac{t^{\prime} \cdot l^{2}}{\alpha} ;(x, y, z)=\frac{\left(x^{\prime}, y^{\prime}, z^{\prime}\right)}{l} ; \psi=\psi^{\prime} \cdot \alpha ;(u, v, w)=\left(u^{\prime}, v^{\prime}, w^{\prime}\right) \frac{l}{\alpha} ;$

$\omega=\omega^{\prime} \cdot \frac{\alpha}{l^{2}} ; T=\frac{T^{\prime}-T_{C}}{T_{H}-T_{C}}$

The obtained dimensionless equations are:

$-\vec{\omega}=\nabla^{2} \vec{\psi}$

$$
\frac{\partial \vec{\omega}}{\partial t}+(\vec{u} . \nabla) \vec{\omega}-(\vec{\omega} . \nabla) \vec{u}=\operatorname{Pr} . \Delta \vec{\omega}+R a \cdot \operatorname{Pr} \cdot\left[\begin{array}{l}
\frac{\partial T}{\partial z} \cos \alpha \\
-\frac{\partial T}{\partial z} \sin \alpha \\
-\frac{\partial T}{\partial x} \cos \alpha+\frac{\partial T}{\partial y} \sin \alpha
\end{array}\right]
$$

$\frac{\partial T}{\partial t}+\vec{u} . \nabla T=\nabla^{2} T$ fluid side

$\frac{\partial T}{\partial t}=\frac{D_{p}}{D_{f}} \nabla^{2} T \quad$ solid side

Some assumptions were considered for energy equations:

The energy equation is solved in the fluid domain. At the solid-liquid interface, the boundary condition is expressed by:

$\left(\frac{\partial T}{\partial y}\right)_{f}=R_{c}\left(\frac{\partial T}{\partial y}\right)_{p}$

with $R_{c}=k_{p} / k_{f}$, is the thermal conductivities ratio.

The control volume finite difference method is used to discretize equations (5-7). The central-difference scheme is 
used for treating convective terms and the fully implicit procedure to discretize the temporal derivatives. The successive relaxation iterating scheme is used to solve the resulting non-linear algebraic equations. The grid is uniform in all directions with additional nodes on boundaries. The time step $10^{-4}$ and spatial mesh $51 \times 151 \times 76$ are retained to carry out all numerical tests. The solution is considered acceptable when the following convergence criterion is satisfied for each step of time:

$\sum_{i}^{1,2,3} \frac{\max \left|\psi_{i}^{n}-\psi_{i}^{n-1}\right|}{\max \left|\psi_{i}^{n}\right|}+\max \left|T_{i}^{n}-T_{i}^{n-1}\right| \leq 10^{-5}$

The boundary conditions for the considered model are given as follows:

Temperature:

$T=1$ à $x=0, T=0$ for $x=1$

$\frac{\partial T}{\partial n}=0$ on all walls (adiabatic).

Vorticity :

$\omega_{x}=0, \omega_{y}=-\frac{\partial u_{z}}{\partial x}, \omega_{z}=\frac{\partial u_{y}}{\partial x}$ at $x=0$ and 1

$\omega_{x}=\frac{\partial u_{z}}{\partial y}, \omega_{y}=0, \omega_{z}=-\frac{\partial u_{x}}{\partial y}$ at $y=0$ et 1

$\omega_{x}=-\frac{\partial u_{y}}{\partial z}, \omega_{y}=\frac{\partial u_{x}}{\partial z}, \omega_{z}=0$ at $z=0$ et 1

Vector potential

$\frac{\partial \Psi_{x}}{\partial x}=\Psi_{y}=\Psi_{z}=0$ at $x=0$ et 1

$\Psi_{x}=\frac{\partial \Psi_{y}}{\partial y}=\Psi_{z}=0$ at $y=0$ et 1

$\Psi_{x}=\Psi_{y}=\frac{\partial \Psi_{z}}{\partial z}=0 \quad$ at $\quad z=0$ et 1

Velocity

$u_{x}=u_{y}=u_{z}=0$ on all walls

Local and average Nusselt at hot wall is given as follows:

$N u=\left.\frac{\partial T}{\partial x}\right|_{x=0} ; N u m=\int_{0}^{1} \int_{0}^{1} N u . \partial y . \partial z$

Equations (5-7) are written is the scalar form as:

$\frac{\partial \omega_{x}}{\partial t}+\frac{\partial}{\partial x}\left[u_{x} \cdot \omega_{x}-\operatorname{Pr} \cdot \frac{\partial \omega_{x}}{\partial x}\right]+$

$\frac{\partial}{\partial y}\left[u_{y} \cdot \omega_{x}-\operatorname{Pr} \cdot \frac{\partial \omega_{x}}{\partial y}\right]+\frac{\partial}{\partial z}\left[u_{z} \cdot \omega_{x}-\operatorname{Pr} \cdot \frac{\partial \omega_{x}}{\partial z}\right]$

$=\omega_{x} \cdot \frac{\partial u_{x}}{\partial x}+\omega_{y} \cdot \frac{\partial u_{x}}{\partial y}+\omega_{z} \cdot \frac{\partial u_{x}}{\partial z}+$

Ra.Pr. $\frac{\partial T}{\partial z} \cdot \cos (\alpha)$ $\frac{\partial \omega_{y}}{\partial t}+\frac{\partial}{\partial x}\left[u_{x} \cdot \omega_{y}-\operatorname{Pr} \cdot \frac{\partial \omega_{y}}{\partial x}\right]+$

$\frac{\partial}{\partial y}\left[u_{y} \cdot \omega_{y}-\operatorname{Pr} \cdot \frac{\partial \omega_{y}}{\partial y}\right]+\frac{\partial}{\partial z}\left[u_{z} \cdot \omega_{y}-\operatorname{Pr} \cdot \frac{\partial \omega_{y}}{\partial z}\right]$

$=\omega_{x} \cdot \frac{\partial u_{y}}{\partial x}+\omega_{y} \cdot \frac{\partial u_{y}}{\partial y}+\omega_{z} \cdot \frac{\partial u_{y}}{\partial z}-$

Ra.Pr. $\frac{\partial T}{\partial z} \cdot \sin (\alpha)$

$\frac{\partial \omega_{z}}{\partial t}+\frac{\partial}{\partial x}\left[u_{x} . \omega_{z}-\operatorname{Pr} \cdot \frac{\partial \omega_{z}}{\partial x}\right]+$

$\frac{\partial}{\partial y}\left[u_{y} . \omega_{z}-\operatorname{Pr} \cdot \frac{\partial \omega_{z}}{\partial y}\right]+\frac{\partial}{\partial z}\left[u_{z} \cdot \omega_{z}-\operatorname{Pr} \cdot \frac{\partial \omega_{z}}{\partial z}\right]$

$=\omega_{x} \cdot \frac{\partial u_{z}}{\partial x}+\omega_{y} \cdot \frac{\partial u_{z}}{\partial y}+\omega_{z} \cdot \frac{\partial u_{z}}{\partial z}-$

$\frac{\partial T}{\partial x} \cos \alpha+\frac{\partial T}{\partial y} \sin \alpha$

$\frac{\partial T}{\partial t}+\frac{\partial}{\partial x}\left[u_{x} \cdot T-\frac{\partial T}{\partial x}\right]+\frac{\partial}{\partial y}\left[u_{y} \cdot T-\frac{\partial T}{\partial y}\right]+$

$\frac{\partial}{\partial z}\left[u_{z} \cdot \omega_{z}-\frac{\partial T}{\partial z}\right]=0$

All the above equations can be written according to a general form as flowing:

$$
\begin{aligned}
& \frac{\partial \Phi}{\partial t}+\frac{\partial}{\partial x}\left(u_{x} . \Phi-\Gamma_{\Phi} \frac{\partial \Phi}{\partial x}\right)+ \\
& \frac{\partial}{\partial y}\left(u_{y} . \Phi-\Gamma_{\Phi} \frac{\partial \Phi}{\partial y}\right)+ \\
& \frac{\partial}{\partial z}\left(u_{z} . \Phi-\Gamma_{\Phi} \frac{\partial \Phi}{\partial z}\right)=S_{\Phi}
\end{aligned}
$$

With:

○ $\Phi: \mathrm{T}, \omega_{x}, \omega_{y}$ or $\omega_{z}$

○ $\Gamma_{\Phi}:$ dimensionless coefficient

○ $S_{\Phi}:$ source term

Thus, the general equation can be written as:

$\frac{\partial \Phi}{\partial t}+\frac{\partial L_{x}}{\partial x}+\frac{\partial L_{y}}{\partial y}+\frac{\partial L_{z}}{\partial z}=S_{\Phi}$

With: $L_{x}=u_{x} . \Phi-\Gamma_{\Phi} \frac{\partial \Phi}{\partial x}, L_{y}=u_{y} . \Phi-\Gamma_{\Phi} \frac{\partial \Phi}{\partial y}$

and $L_{z}=u_{z} \cdot \Phi-\Gamma_{\Phi} \frac{\partial \Phi}{\partial z}$

Using a pure implicit scheme, the system of algebraic coupled equations in three-dimensional formulation can be written as: 
$a_{P}^{l} I_{P}^{l}=a_{W}^{l} I_{W}^{l}+a_{E}^{l} I_{E}^{l}+a_{S}^{l} I_{S}^{l}+a_{N}^{l} I_{N}^{l}+$ $a_{B}^{l} I_{B}^{l}+a_{F}^{l} I_{F}^{l}+b_{P}$

With:

$$
\begin{aligned}
& a_{W}^{l}=\Delta A_{w}\left\|-N_{w}^{l}, O\right\|, a_{E}^{l}=\Delta A_{e}\left\|-N_{e}^{l}, O\right\|, \\
& a_{S}^{l}=\Delta A_{s}\left\|-N_{s}^{l}, 0\right\|, a_{N}^{l}=\Delta A_{n}\left\|-N_{n}^{l}, O\right\|, \\
& a_{B}^{l}=\Delta A_{b}\left\|-N_{b}^{l}, O\right\|, \quad a_{F}^{l}=\Delta A_{f}\left\|-N_{f}^{l}, O\right\|, \\
& b_{P}=\beta R_{P} \Delta \mathrm{v}_{P} \\
& a_{P}^{l}=\Delta A_{w}\left\|N_{w}^{l}, 0\right\|+\Delta A_{e}\left\|N_{e}^{l}, 0\right\|+\Delta A_{s}\left\|N_{s}^{l}, O\right\|+ \\
& \Delta A_{n}\left\|N_{n}^{l}, O\right\|+\Delta A_{b}\left\|N_{b}^{l}, O\right\|+\Delta A_{f}\left\|N_{f}^{l}, O\right\|+\beta \Delta \mathrm{v}_{P}
\end{aligned}
$$

e, w, n, s, b and t, denote the faces of control volume centered in $\mathrm{P}, \mathrm{E}, \mathrm{W}, \mathrm{N}, \mathrm{S}, \mathrm{B}$ and $\mathrm{T}$, denote the nodes around the nodal point $\mathrm{P}\|A, B\|$ gives the maximum between $\mathrm{A}$ and B.

The governing equations are developed as follow:

- Energy equation $(\Phi=T)$ :

$a_{p} T_{p}=a_{E} T_{E}+a_{W} T_{W}+a_{N} T_{N}+a_{S} T_{S}+a_{H} T_{H}+$ $a_{B} T_{B}+b_{p}$

With : $b_{p}=T_{p}^{\circ} \frac{\Delta x \cdot \Delta y \cdot \Delta z}{\Delta t} \frac{1}{2}$

- Vorticity equation; x-component $\left(\Phi=\omega_{x}\right)$$$
a_{p} \omega_{x p}=a_{E} \omega_{x E}+a_{W} \omega_{x W}+a_{N} \omega_{x N}+a_{S} \omega_{x S}+
$$$$
a_{H} \omega_{x H}+a_{B} \omega_{x B}+b_{p}
$$

with:

$b_{p}=\omega_{x p}^{\circ} \frac{\Delta x \cdot \Delta y \cdot \Delta z}{\Delta t}+\omega_{x p} \cdot\left(\frac{V_{x E}-V_{x w}}{2}\right) \cdot \Delta y \cdot \Delta z+$

$\omega_{y p} \cdot\left(\frac{V_{x S}-V_{x N}}{2}\right) \cdot \Delta x \cdot \Delta z+$

$\omega_{z p} \cdot\left(\frac{V_{x H}-V_{x B}}{2}\right) \cdot \Delta x \cdot \Delta y+$

$R a . \operatorname{Pr} .\left(\frac{T_{H}-T_{B}}{2}\right) \cdot \cos \alpha \cdot \Delta x \cdot \Delta y$

- Vorticity equation; x-component $\left(\Phi=\omega_{y}\right)$ :

$a_{p} \omega_{x p}=a_{E} \omega_{y E}+a_{W} \omega_{y W}+a_{N} \omega_{y N}+$

$a_{S} \omega_{y S}+a_{H} \omega_{y H}+a_{B} \omega_{y B}+b_{p}$

with:

$$
\begin{aligned}
& b_{p}=\omega_{y p}^{\circ} \frac{\Delta x \cdot \Delta y \cdot \Delta z}{\Delta t}+\omega_{y p} \cdot\left(\frac{V_{y E}-V_{y w}}{2}\right) \cdot \Delta y \cdot \Delta z+ \\
& \omega_{y p} \cdot\left(\frac{V_{y S}-V_{y N}}{2}\right) \cdot \Delta x \cdot \Delta z- \\
& \omega_{z p} \cdot\left(\frac{V_{y H}-V_{y B}}{2}\right) \cdot \Delta x \cdot \Delta y+ \\
& R a \cdot \operatorname{Pr} \cdot\left(\frac{T_{H}-T_{B}}{2}\right) \cdot \sin \alpha \cdot \Delta x \cdot \Delta y
\end{aligned}
$$

- Vorticity equation; X-component $\left(\Phi=\omega_{z}\right)$ :

$a_{p} \omega_{z p}=a_{E} \omega_{z E}+a_{W} \omega_{z W}+a_{N} \omega_{z N}+$

$a_{S} \omega_{z S}+a_{H} \omega_{z H}+a_{B} \omega_{z B}+b_{p}$

with:

$b_{p}=\omega_{z p}^{\circ} \frac{\Delta x \cdot \Delta y \cdot \Delta z}{\Delta t}+\omega_{z p} \cdot\left(\frac{V_{z E}-V_{z w}}{2}\right) \cdot \Delta y \cdot \Delta z+$

$\omega_{z p} \cdot\left(\frac{V_{z S}-V_{z N}}{2}\right) \cdot \Delta x \cdot \Delta z+$

$\omega_{z p} \cdot\left(\frac{V_{z H}-V_{z B}}{2}\right) \cdot \Delta x \cdot \Delta y-$

$R a \cdot \operatorname{Pr} \cdot\left(\frac{T_{E}-T_{W}}{2}\right) \cdot \cos \alpha \cdot \Delta y \cdot \Delta z+$

$\operatorname{Ra} . \operatorname{Pr} .\left(\frac{T_{N}-T_{S}}{2}\right) \sin \alpha . \Delta x . \Delta z$

- vector potential equations

$$
\psi_{x p}=\frac{1}{2 .\left(\frac{1}{\Delta x^{2}}+\frac{1}{\Delta y^{2}}+\frac{1}{\Delta z^{2}}\right)}\left(\begin{array}{l}
\frac{\psi_{x E}+\psi_{x W}}{\Delta x^{2}}+ \\
\frac{\psi_{x N}+\psi_{x S}}{\Delta y^{2}}+ \\
\frac{\psi_{x H}+\psi_{x B}}{\Delta z^{2}}+\omega_{x p}
\end{array}\right)
$$

$\psi_{y p}=\frac{1}{2 \cdot\left(\frac{1}{\Delta x^{2}}+\frac{1}{\Delta y^{2}}+\frac{1}{\Delta z^{2}}\right)}\left(\begin{array}{l}\frac{\psi_{y E}+\psi_{y W}}{\Delta x^{2}}+ \\ \frac{\psi_{y N}+\psi_{y S}}{\Delta y^{2}}+ \\ \frac{\psi_{y H}+\psi_{y B}}{\Delta z^{2}}+\omega_{y p}\end{array}\right)$

$$
\psi_{z p}=\frac{1}{2 \cdot\left(\frac{1}{\Delta x^{2}}+\frac{1}{\Delta y^{2}}+\frac{1}{\Delta z^{2}}\right)}\left(\begin{array}{l}
\frac{\psi_{z E}+\psi_{z W}}{\Delta x^{2}}+ \\
\frac{\psi_{z N}+\psi_{z S}}{\Delta y^{2}}+ \\
\frac{\psi_{z H}+\psi_{z B}}{\Delta z^{2}}+\omega_{z p}
\end{array}\right)
$$

Entropy production is the result of an imbalance state, caused by thermal and viscous irreversibilities 
Indeed, the temperature gradient is the origin of the entropy production called the "thermal entropy", while the dissipation energy leads to the production of the entropy called "viscous entropy" so the total generated entropy can be defined as the sum of these two quantities:

$S_{\text {gen }}^{\prime}=S^{\prime}{ }_{t h}+S^{\prime}{ }_{f r}$

In general, the generated entropy is given as follows:

$S_{\text {gen }}^{\prime}=-\frac{1}{T^{\prime 2}} \cdot \vec{q} \cdot \vec{\nabla} T^{\prime}+\frac{\mu}{T^{\prime}} \cdot \phi^{\prime}$

with:

$\vec{q}=-k \cdot g r a \vec{d} T$

The first term represents the generated entropy due to the temperature gradient, while the second is that due to the friction effects. $\phi^{\prime}$ is the dissipation function which represents the degradation of interior heat forces.

For an incompressible flow, this dissipation function is expressed by:

$\phi^{\prime}=2\left[\left(\frac{\partial u_{x}^{\prime}}{\partial x^{\prime}}\right)^{2}+\left(\frac{\partial u_{y}^{\prime}}{\partial y^{\prime}}\right)^{2}+\left(\frac{\partial u_{z}^{\prime}}{\partial z^{\prime}}\right)^{2}\right]+$

$\left(\frac{\partial u_{y}^{\prime}}{\partial x^{\prime}}+\frac{\partial u_{x}^{\prime}}{\partial y^{\prime}}\right)^{2}+\left(\frac{\partial u_{z}^{\prime}}{\partial y^{\prime}}+\frac{\partial u_{y}^{\prime}}{\partial z^{\prime}}\right)^{2}+\left(\frac{\partial u_{x}^{\prime}}{\partial z^{\prime}}+\frac{\partial u_{z}^{\prime}}{\partial x^{\prime}}\right)^{2}$

Hence the total generated entropy is expressed by:

$$
\begin{aligned}
& S_{\text {gen }}^{\prime}=\frac{k}{T_{0}^{2}}\left[\left(\frac{\partial T^{\prime}}{\partial x^{\prime}}\right)^{2}+\left(\frac{\partial T^{\prime}}{\partial y^{\prime}}\right)^{2}+\left(\frac{\partial T^{\prime}}{\partial z^{\prime}}\right)^{2}\right] \\
& +\frac{\mu}{T_{0}}\left\{2\left[\left(\frac{\partial u_{x}^{\prime}}{\partial x^{\prime}}\right)^{2}+\left(\frac{\partial u_{y}^{\prime}}{\partial y^{\prime}}\right)^{2}+\left(\frac{\partial u_{z}^{\prime}}{\partial z^{\prime}}\right)^{2}\right]\right. \\
& \left.+\left(\frac{\partial u_{y}^{\prime}}{\partial x^{\prime}}+\frac{\partial u_{x}^{\prime}}{\partial y^{\prime}}\right)^{2}+\left(\frac{\partial u_{z}^{\prime}}{\partial y^{\prime}}+\frac{\partial u_{y}^{\prime}}{\partial z^{\prime}}\right)^{2}+\left(\frac{\partial u_{x}^{\prime}}{\partial z^{\prime}}+\frac{\partial u_{z}^{\prime}}{\partial x^{\prime}}\right)^{2}\right\}
\end{aligned}
$$

Using the dimensionless parameters, the generated entropy number (dimensionless local entropy generated) is expressed as following:

$$
\begin{aligned}
& N_{s}=\left[\left(\frac{\partial T}{\partial x}\right)^{2}+\left(\frac{\partial T}{\partial y}\right)^{2}+\left(\frac{\partial T}{\partial z}\right)^{2}\right] \\
& +\phi \cdot\left\{\begin{array}{l}
2\left[\left(\frac{\partial u_{x}}{\partial x}\right)^{2}+\left(\frac{\partial u_{y}}{\partial y}\right)^{2}+\left(\frac{\partial u_{z}}{\partial z}\right)^{2}\right]+ \\
{\left[\left(\frac{\partial u_{y}}{\partial x}+\frac{\partial u_{x}}{\partial y}\right)^{2}+\left(\frac{\partial u_{z}}{\partial y}+\frac{\partial u_{y}}{\partial z}\right)^{2}+\left(\frac{\partial u_{x}}{\partial z}+\frac{\partial u_{z}}{\partial x}\right)^{2}\right]}
\end{array}\right\}
\end{aligned}
$$

with $\varphi=\frac{\mu \alpha^{2} T_{m}}{l^{2} k \Delta T^{2}}$ is the irreversibility distribution coefficient.

The total dimensionless generated entropy is written as:

$$
S_{t o t}=\int_{v} N_{s} d v=\int_{v}\left(N_{s-t h}+N_{s-f r}\right) d v=S_{t h}+S_{f r}
$$

\section{RESULTS AND DISCUSSIONS}

A numerical study of three-dimensional natural convection heat transfer in an inclined rectangular cavity assimilated to a solar collector was made to investigate the effect of the inclination angles on the temperature repartition, flow behavior and entropy generation for different length of partitions and different Rayleigh numbers. The average Nusselt number for the different inclinations and length partitions will be also discussed.

Results are presented for $\operatorname{Pr}=0.71$ and a range of angles $0^{\circ} \leq$ $\alpha \leq 90^{\circ}$; the Rayleigh numbers and the length of partitions are varied respectively from $\mathrm{Ra}=10^{3}$ to $10^{5}$ and $\mathrm{L}_{\mathrm{p}}=0.2$, 0.5 and 0.8 . The dimensionless irreversibility distribution ratio $\varphi$, is fixed at $10^{-5}$. Partitions and cover are assumed to be in Plexiglas $\left(\mathrm{k}=1.8 \mathrm{~W} \cdot \mathrm{m}^{-1} \cdot \mathrm{K}^{-1}\right) R_{c} \approx 7$.

Figure 2 and 3 present, the three-dimensional iso-surfaces of temperature for different inclinations, Rayleigh numbers and partitions length. For $\mathrm{Ra}=10^{3}$, the iso-surfaces of temperature are almost quasi-parallel, the regime is conductive and the presence of the partitions seems without influence.

The wavy ordered aspect begin for $\mathrm{Ra}=10^{4}$, the isosurfaces present a slight distortion in the center of the gravity of the cavity for the cases of $L_{p}=0.2$ and 0.5 , for this last case $\left(L_{p}=0.5\right)$ the gradient of the temperature is accentuated in the upper part near the cold wall and the lower part near the hot wall. For $\mathrm{L}_{\mathrm{p}}=0.8$ the quasi-parallel behavior reappears showing the effect of the partitions to put in order the thermal iso-surfaces by increasing the length of partitions. For $\mathrm{Ra}=10^{5}$, the distortion increases, the excessive gradient in upper part of the cold wall intensifies and it occupy the major volume of the cavity.

The length of partitions effect is more evident for high Rayleigh numbers. We can notice a symmetrical distribution for $L_{p}=0.8$ for all Rayleigh numbers range, this symmetry is less evident for $L_{p}=0.5$ and 0.2 and we can conclude that by increasing the length of partitions, the iso-surfaces of temperature distribution become more and more organized and the wavy behavior more and more evident.

Figure 4 present a comparison, at high Rayleigh number $\mathrm{Ra}=10^{5}$, between the behaviors of the isotherms projection in the $x-y$ plan at $z=0.5$, with the length partitions and the inclination angles. At high Rayleigh number the length partitions effect is evident for all the angles and the intensity of isotherms lines patterns depends from this length.

By increasing the tilted angles, the isotherm lines behaviors variation is so evident in the middle of the cavity, but near the active walls, for most cases, we can notice the existence of an excessive gradient. This gradient is located near the cold wall in the upper part and near the hot wall in the inferior part of cavity; the increase of angles inclination ad the length partitions tend to spread this excessively along those active walls and we found at $\alpha=90^{\circ}$ the accentuated gradient near the whole active walls. By increasing the length partitions, we found also this spread of the excessive gradient but we notice a decrease of intensity from a length to other. The behaviors variation of the isotherm lines in the middle of the cavity due to the increase of the inclination angles tends to the formation of cells. Only for the case of $\alpha=90^{\circ}$ we can notice the existence of cells special in the space between the partitions walls. 


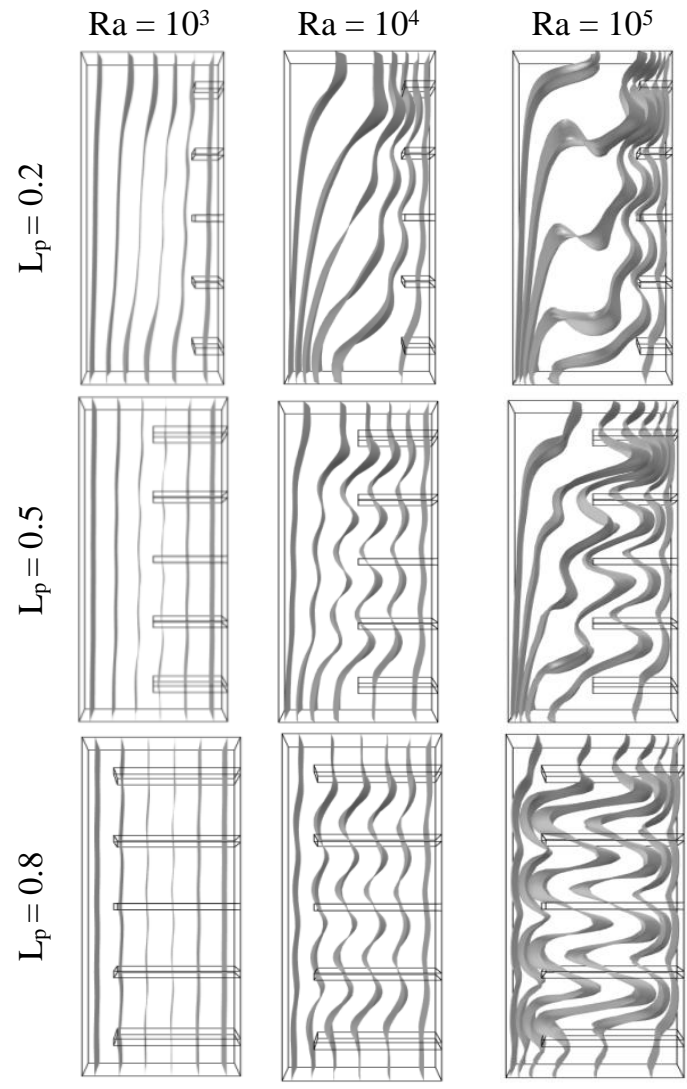

Figure 2. iso-surfaces of temperature for $\alpha=0^{\circ}$ and different $\mathrm{Ra}$ and $\mathrm{L}_{\mathrm{p}}$
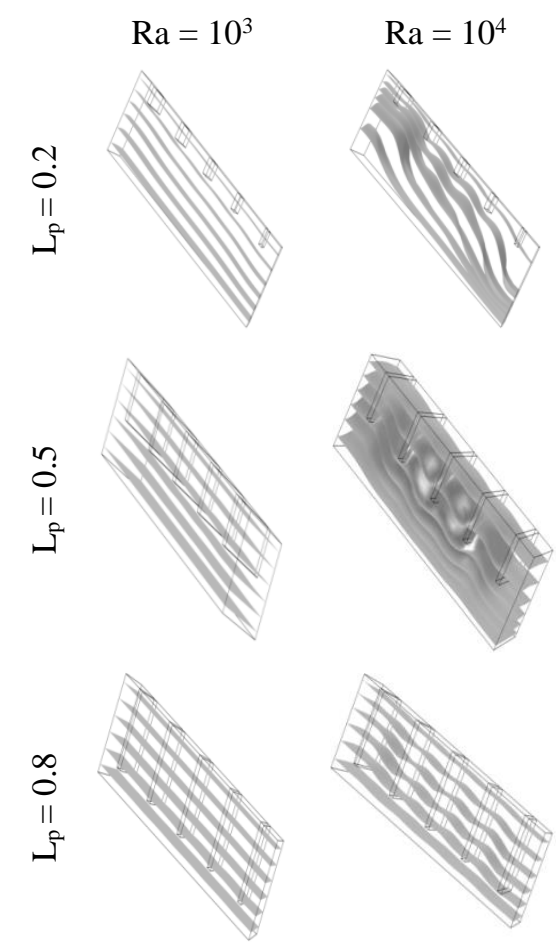

Figure 3. Iso-surfaces of temperature for $\alpha=60^{\circ}$ and different $\mathrm{Ra}$ and $\mathrm{L}_{\mathrm{p}}$

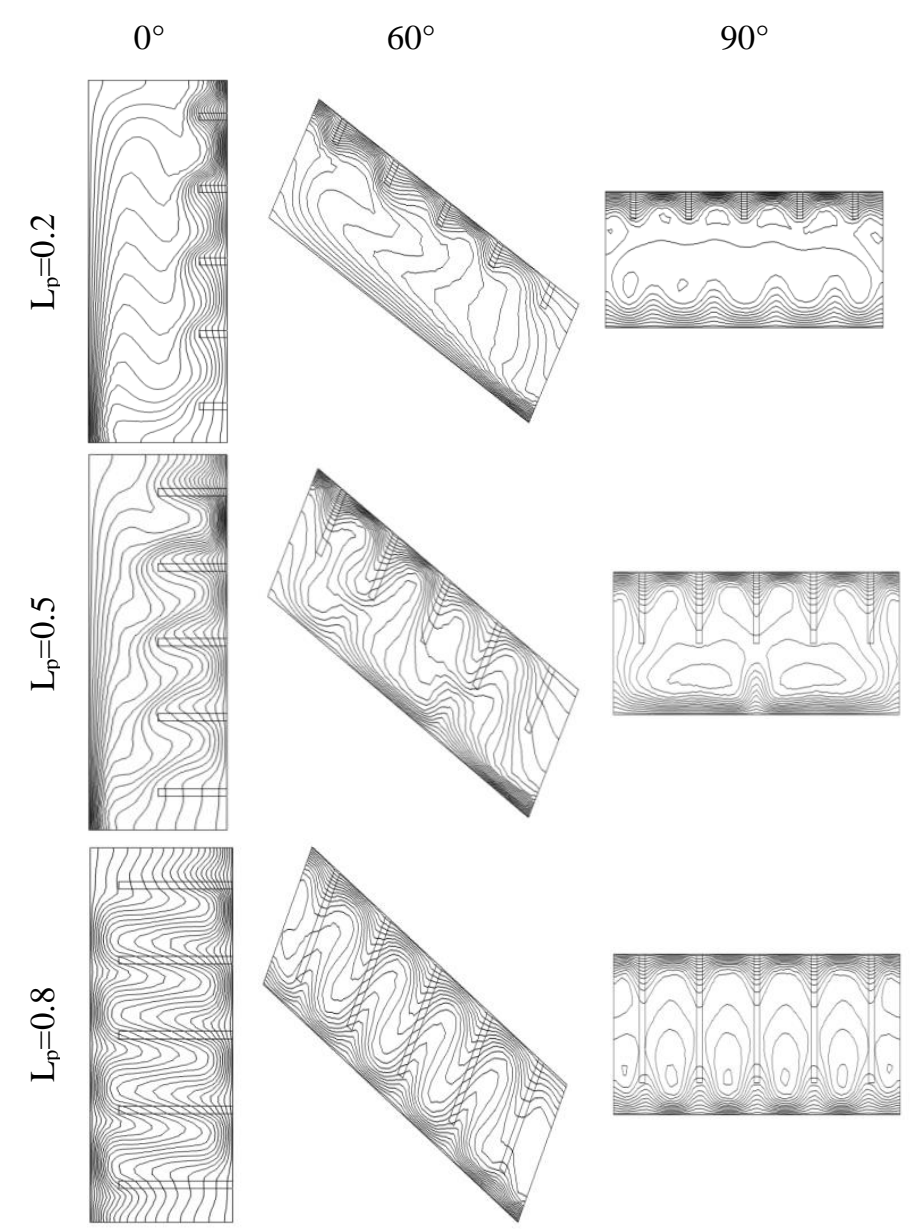

Figure 4. Isotherms at $\mathrm{z}=0.5$ for $\mathrm{Ra}=10^{5}$ and different $\mathrm{L}_{\mathrm{p}}$ and $\alpha$

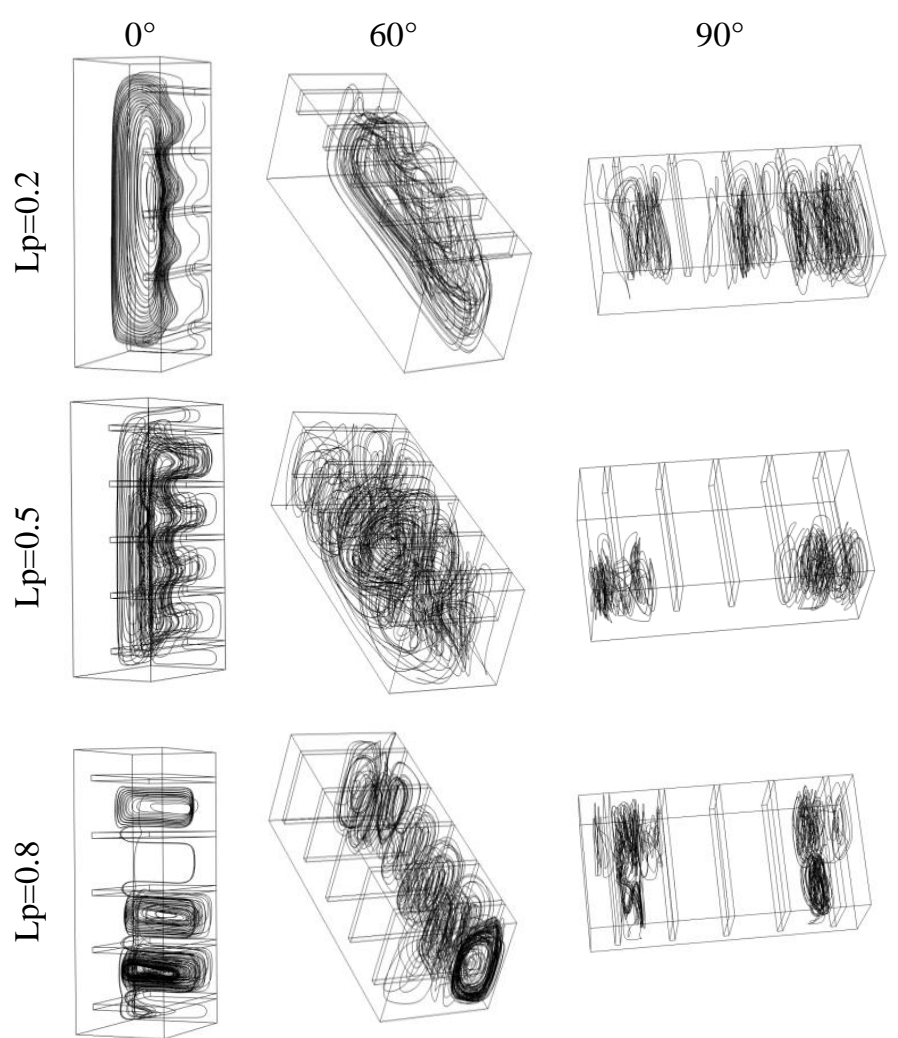

Figure 5. Some particles trajectories for $\mathrm{Ra}=10^{5}$ and different $\mathrm{L}_{\mathrm{p}}$ and $\alpha$. 
$0^{\circ}$

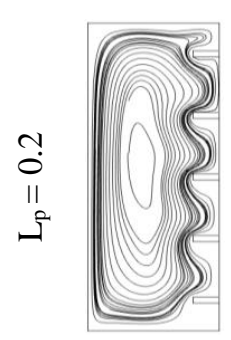

$60^{\circ}$

$90^{\circ}$

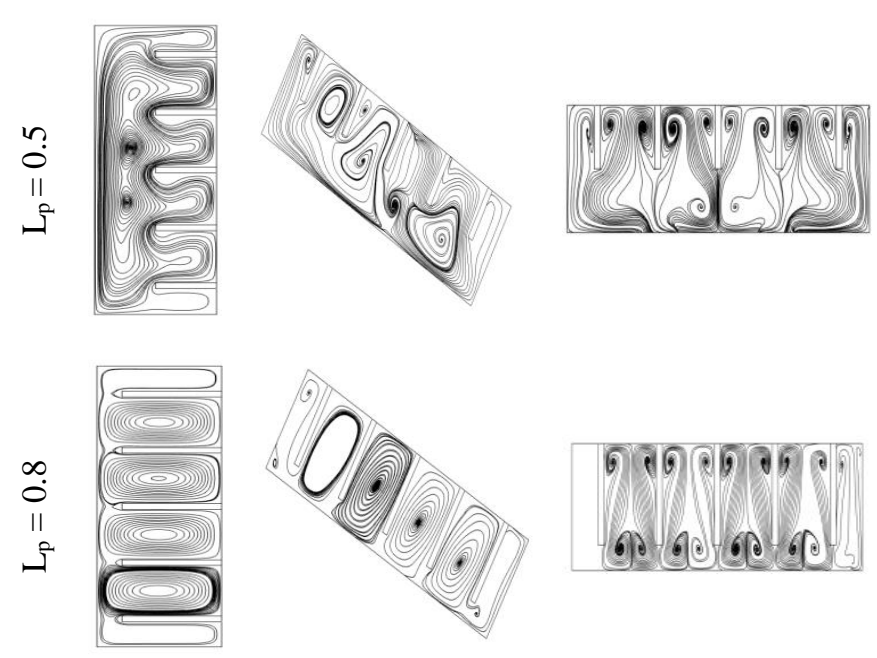

Figure 6. Velocity vector projection at $\mathrm{z}=0.5$ for $\mathrm{Ra}=10^{5}$ and different $\mathrm{L}_{\mathrm{p}}$ and $\alpha$

For this angle of $90^{\circ}$, a main cell is obtained at $\mathrm{L}_{\mathrm{p}}=0.2$ filling all the enclosure, with small little cells between the partitions with two others inside the main one and the effect of partition forms on the isotherm pattern is so evident.

By increasing $L_{p}$, the dimension of main cell becomes smaller, it is divided to secondary concentric cells and we notice a symmetric behavior increasing with the increase of the length partitions.

Figure 5and 6 present the particles trajectories and vector velocity projection for $\mathrm{Ra}=10^{5}$ at central xy-plan. The regime is multi-cellular even for low length partitions, but the flow structure become more and more complex by increasing the angle inclinations. In fact for $L_{p}=0.2$, the flow seems to be organized for $\alpha=0^{\circ}$ and it is characterized by a main centered vortex occupying the major portion of the cavity. For $\alpha=60^{\circ}$ the flow become disordered and the vortex is decentered downward. The $3 \mathrm{D}$ character is more pronounced with a modified structure at $\alpha=90^{\circ}$ at which the collector is in horizontal position; the flow changes direction and turns around the $\mathrm{x}$-axis and more irregularity is observed due to the stronger buoyancy forces.

For $L_{p}=0.5$, as the partition lengths increase, four equal vortexes appear with tow little ones near the extreme partitions for $\alpha=0^{\circ}$. For $\alpha=60^{\circ}$ and $90^{\circ}$ the flow become disordered. For $\mathrm{L}_{\mathrm{p}}=0.8$, we notice there is a symmetry at low inclination angles, the vortexes have the same size and the partitions effect. For $\alpha=90^{\circ}$ the flow turns around the $\mathrm{x}$ axis. Due to the small distance between the walls and partitions, rectangular shaped cells are formed at the bottom and the top of the enclosure for the cases of $L_{p}=0.5$ and 0.8 even for $\alpha=90^{\circ}$. The increase of $\mathrm{L}_{\mathrm{p}}$ at a fixed angle tends to put the flow in an organized behavior.

Average Nusselt number versus Rayleigh numbers has been illustrated for different inclination angles for a fixed
Length partitions in fig. 7. Nusselt number increases with the Rayleigh number for all inclinations, which is due to the increase of the buoyancy forces at higher Rayleigh numbers.

At low Rayleigh numbers, the average Nusselt number seems not to change significantly with the inclination angle which is due to the conduction dominated mechanism at low Rayleigh number. At high Rayleigh numbers, the inclination effect is more evident, Nusselt number is more pronounced and the maximum occurs at $\alpha=90^{\circ}$.
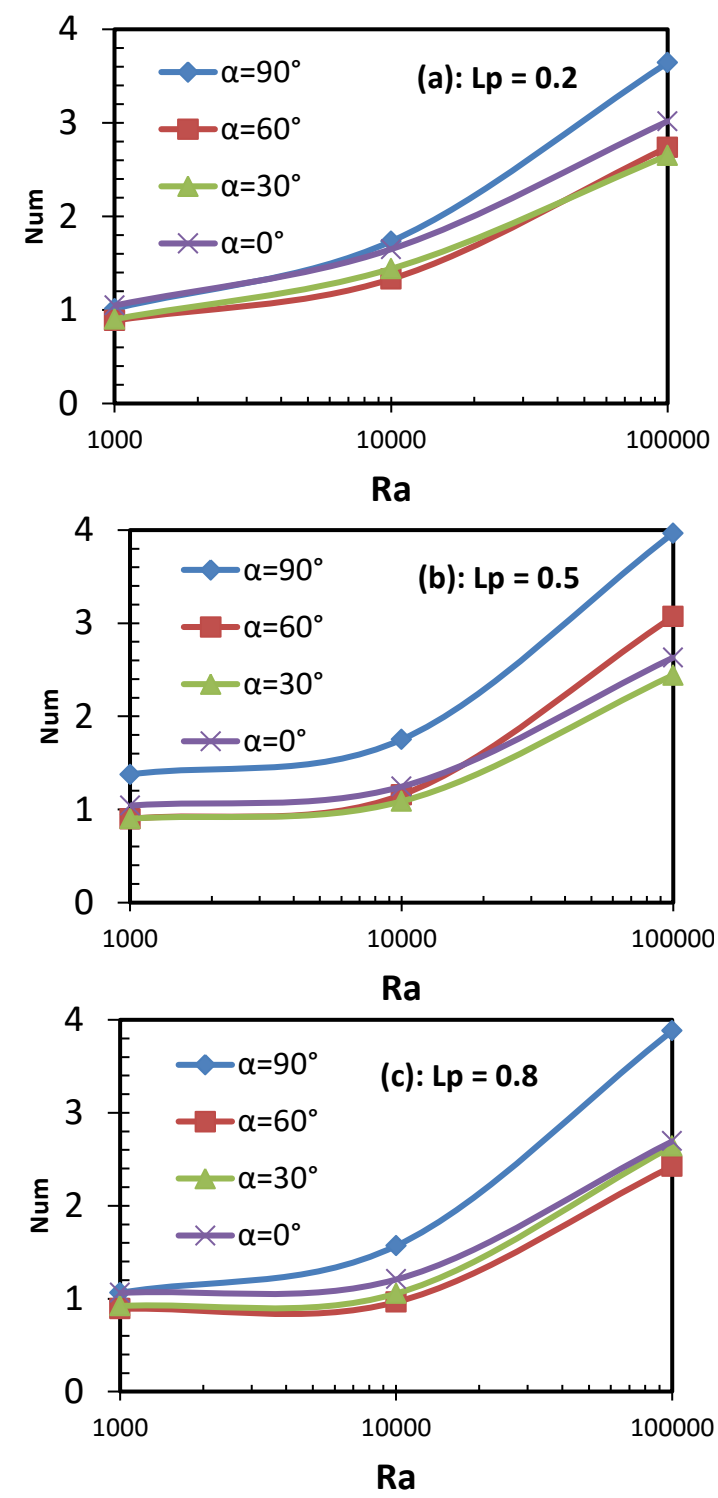

Figure 7. verage Nusselt number versus Rayleigh numbers for different inclination angles, for partitions lengths : (a): $\mathrm{L}_{\mathrm{p}}$ $=0.2 ;(\mathrm{b}): \mathrm{L}_{\mathrm{p}}=0.5 ;(\mathrm{c}): \mathrm{L}_{\mathrm{p}}=0.8$

By considering the application of partitions, we conclude that Nusselt number does not change significantly with the length partitions; when studying this evaluation at a given inclination angle and Rayleigh number, the results affirm this last conclusion; indeed, for $\alpha=90^{\circ}$ for example $\mathrm{Nu}$ increases at $\mathrm{L}_{\mathrm{p}}=0.5$ then decreases when increasing $\mathrm{L}_{\mathrm{p}}$ again to 0.8 but, for $\alpha=30^{\circ}, \mathrm{Nu}$ decrease when $\mathrm{L}_{\mathrm{p}}$ pass from 0.2 to 0.5 and then increase at $\mathrm{L}_{\mathrm{p}}=0.8$; for $\mathrm{Ra} 10^{4}$ at $0^{\circ}$ and $60^{\circ}, \mathrm{Nu}$ deceases with the increase of $L_{p}$. This variation of the average Nusselt number with the length partitions is so weak, Nusselt number remains approximately constant. 
On figure 8 , the local entropy generation for different Rayleigh numbers and inclination angles is depicted. Partition lengths were fixed at $\mathrm{L}_{p}=0.5$ and the cut plan is fixed at $\mathrm{z}=0.5$. Results show that the entropy generation increases with Rayleigh number; it is localized near the walls and mostly located at the right side of the bottom hot wall and around the fins boundary especially for high Rayleigh numbers. At $\alpha=90^{\circ}$, the entropy is concentrated around the bottom side of the partitions for $\mathrm{Ra}=10^{3}$ and $10^{4}$, but for high Rayleigh number, it is located, in addition of the partitions walls, near the active walls. Figure 9 presents the evolution of the total entropy generation versus the Rayleigh number for every inclination angle at $\mathrm{L}_{\mathrm{p}}=0.2$.

It can be observed that the total entropy generation increases as function of Rayleigh number. At low Rayleigh numbers, the variation of total entropy does not vary much as the conduction mechanism dominates and the temperature gradient and the flow field are so weak; but the for high Rayleigh numbers, the increase of the total entropy generation is more evident which can be explained by the increase of the fluid flow and the temperature gradient.

We notice that for $L_{p}=0.2$, the total entropy generation don't vary much with the inclination at low Rayleigh numbers, but for high Rayleigh numbers a small variation is observed;

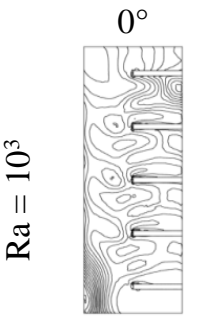

$(0.75,1.46)$

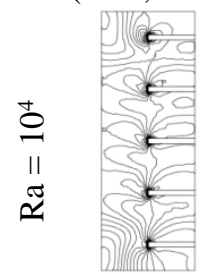

$(0.34,6.53)$

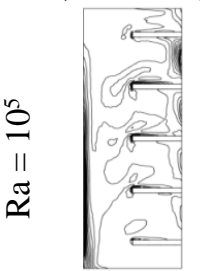

$(2.88,110)$ $60^{\circ}$

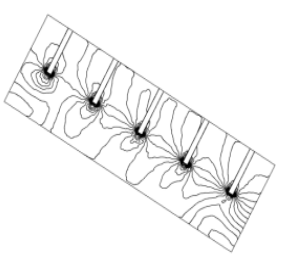

$(0.78,1.4)$

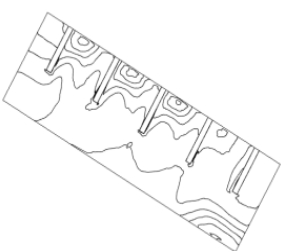

$(0.59,13.8)$

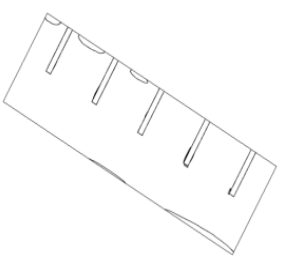

$(32.5,1265)$ $90^{\circ}$

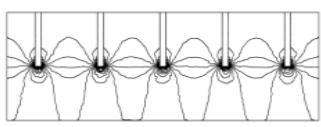

$(0.79,1.74)$

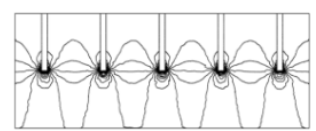

$(0.81,7.52)$

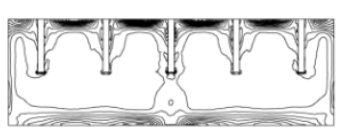

$(2.23,83.5)$
Figure 8. Variation of local entropy generation for $\mathrm{L}_{\mathrm{p}}=$ 0.5 at $\mathrm{z}=0.5$ for different Rayleigh numbers and inclination angles

As illustration figure 10 presents variation of thermal and viscous entropy generations for $\mathrm{L}_{\mathrm{p}}=0.2$ and $\mathrm{L}_{\mathrm{p}}=0.8$ and fixed inclination $\left(\alpha=30^{\circ}\right)$. This figure shows that for a low Rayleigh number, the entropy generation due to the fluid friction irreversibility $S_{\mathrm{fr}}$ is negligible and the entropy generations due to heat transfer $S_{\text {th }}$ is more important and almost equal to the total generated entropy. For high Rayleigh number (from $\mathrm{Ra}=10^{5}$ ), the generated entropy increases and we notice that for $\mathrm{L}_{\mathrm{p}}=0.2$ the entropy due to the fluid friction is higher than the entropy due to heat transfer which is absolutely the contrary in the case of $\mathrm{L}_{\mathrm{p}}=$ 0.8 .

In fact, by the study made for all cases, it turns out that for high Rayleigh number $\left(\mathrm{Ra}=10^{5}\right)$ when the inclination angle is low $\left(\alpha=0^{\circ}\right.$ and $\left.30^{\circ}\right), \mathrm{S}_{\mathrm{fr}}$ is more important than $\mathrm{S}_{\mathrm{th}}$ at low $\left(\mathrm{L}_{\mathrm{p}}=0.2\right.$ and 0.5$)$ but $\mathrm{S}_{\mathrm{th}}$ become higher than $\mathrm{S}_{\mathrm{fr}}$ at high $\mathrm{L}_{\mathrm{p}}$; whereas, for high inclination angles $\left(\alpha=60^{\circ}\right.$ and $\left.90^{\circ}\right), \mathrm{S}_{\mathrm{th}}$ remains dominant at all the length partitions at all Rayleigh numbers.

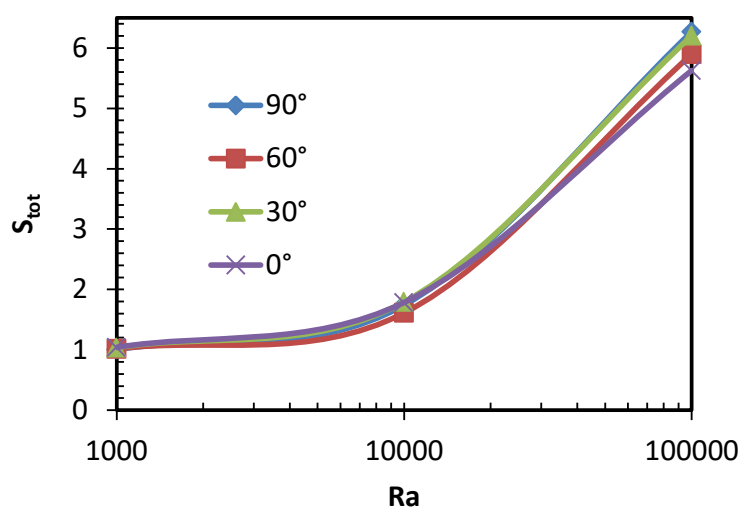

Figure 9. Dimensionless total entropy generation versus Rayleigh Numbers for different inclination angle at $\mathrm{L}_{\mathrm{p}}=0.2$
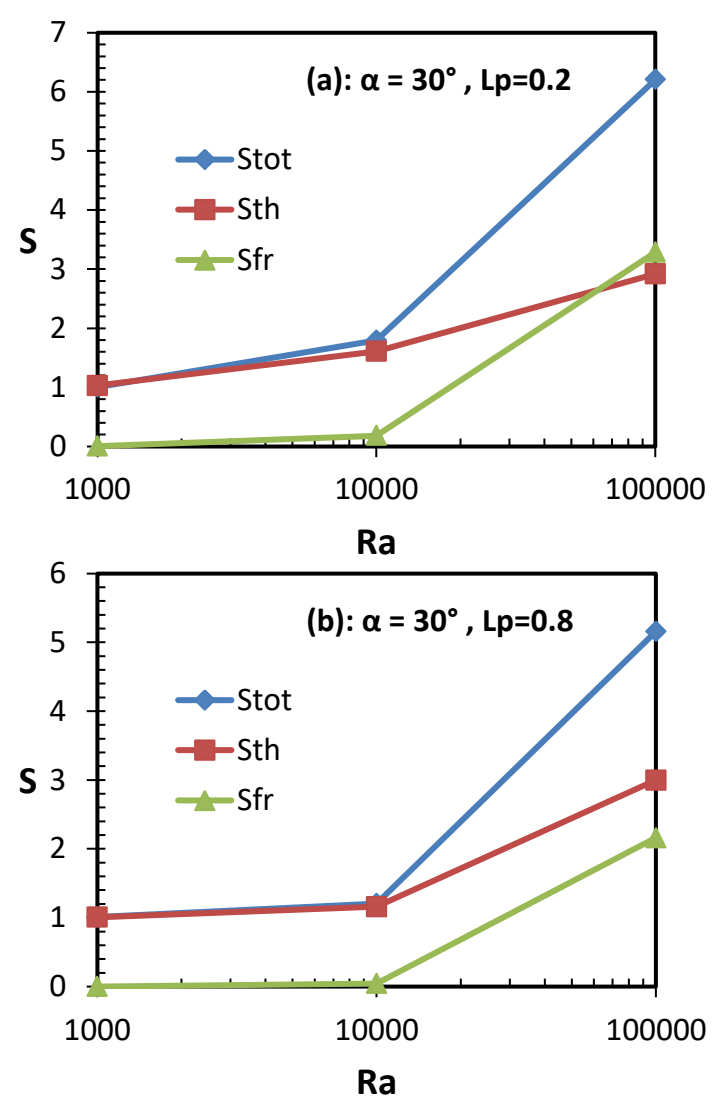

Figure 10. $S_{\text {tot }}, S_{\text {th }}, S_{\text {fr }}$ versus Rayleigh Numbers for inclination angle $\alpha=30^{\circ}$ and length partitions:

$$
\text { (a): } \mathrm{L}_{\mathrm{p}}=0.2 ;(\mathrm{b}): \mathrm{L}_{\mathrm{p}}=0.8
$$

Inclination effect on total entropy generation for different partition lengths Rayleigh numbers is displayed on figure 11. It can be observed that total entropy vary by different ways. The variation is almost decreasing for low $\mathrm{Ra}$ and almost increasing for higher Ra. 

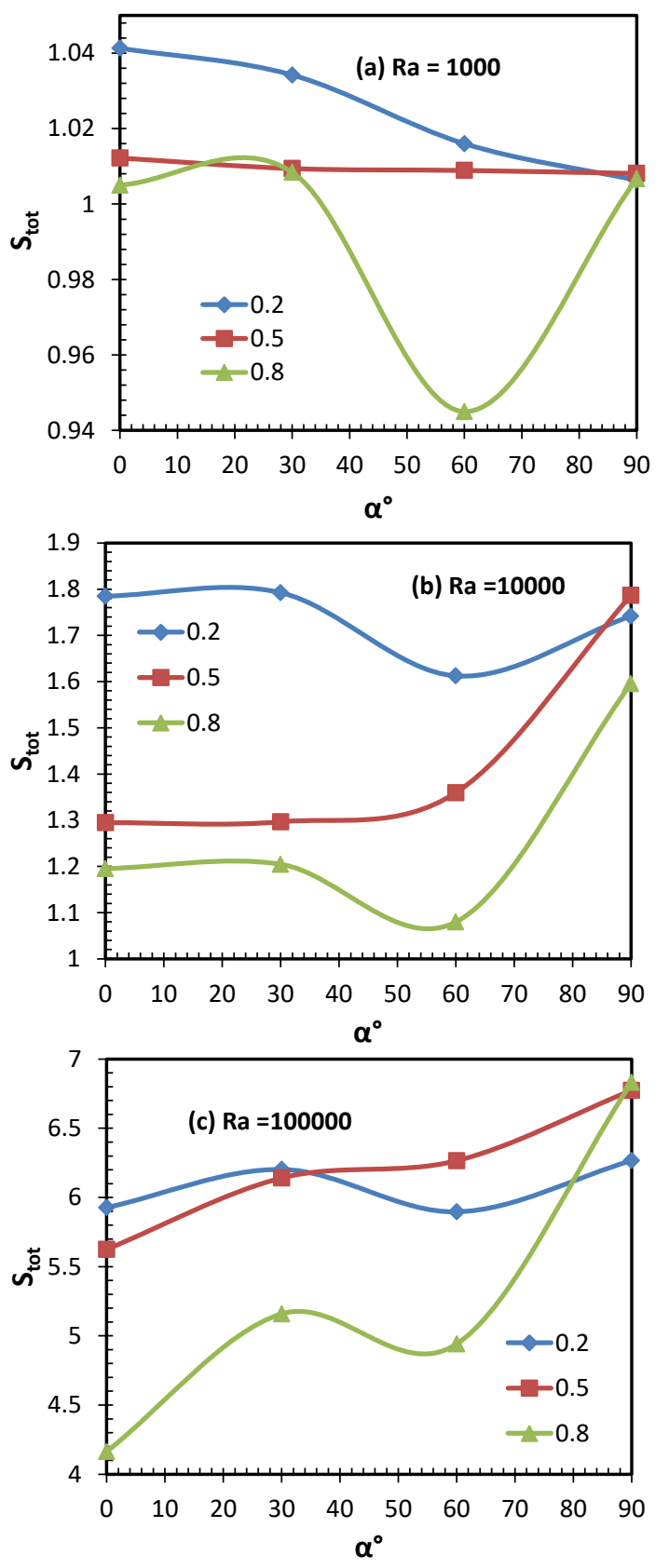

Figure 11. Dimensionless total entropy generation versus inclination angles for different length partitions at: (a): $\mathrm{Ra}=$ $10^{3} ;(\mathrm{b}): \mathrm{Ra}=10^{4} ;(\mathrm{c}): \mathrm{Ra}=10^{5}$

\section{CONCLUSION}

A numerical three-dimensional study of the natural convection and entropy generation in an inclined rectangular equipped with partitions was presented in this paper. Results show that for low Rayleigh numbers, the regime is conductive and there is a symmetrical distribution of temperature, this symmetry disappear by increasing the Rayleigh numbers and the structure become more distorted, the 3D character is more pronounced special for low partitions lengths. At high partitions lengths, the symmetrical distribution tends to reappears even for high Rayleigh numbers.

The average Nusselt number increases with Rayleigh numbers for all the inclination angles at all the length partitions; the results we find show that for low Rayleigh numbers, the average Nusselt number seems not to change significantly with the inclination angle but for high Rayleigh numbers, the inclination effect is more evident, moreover, the Nusselt number does not change significantly with the length partitions

The total entropy generation study shows that it increases with the increase of Rayleigh number. At low Rayleigh numbers, the variation of total entropy does not vary much but, the for high Rayleigh numbers, the increase of the total entropy generation is more evident.

For low Rayleigh number, the entropy generation due to the fluid friction irreversibility is negligible whereas the entropy generations due to heat transfer is more important and almost equal to the total generated entropy; whereas, for high Rayleigh number of $10^{5}$, it turns out that, the entropy generation due to the fluid friction is more important for $\mathrm{L}_{\mathrm{p}}=$ 0.2 and 0.5 at little inclination angles $\left(\alpha=0^{\circ}\right.$ and $\left.30^{\circ}\right)$, but, at high $\mathrm{L}_{\mathrm{p}}$ the contrary happens; whereas, for high inclination angles $\left(\alpha=60^{\circ}\right.$ and $\left.90^{\circ}\right)$, the entropy generations due to heat transfer remains dominant at all the length partitions at all Rayleigh numbers.

\section{REFERENCES}

[1] Hinojosa J.F., Alvarez G., Estrada C.A. (2006). Three-dimensional numerical simulation of the natural convection in an open tilted cubic cavity, Revista Mexicana De Fisica, Vol. 52, No. 2, pp. 111-119.

[2] Sharma R.P. (2013). A numerical analysis of threedimensional Darcy model in an inclined rectangular porous box using SAR technique, International Journal of Mechanical Engineering and Technology, Vol. 4, No. 3, pp. 554-561.

[3] Kolsi L. (2015). Heat and mass transfer in 3D inclined lid-driven solar distiller, International Journal of Fluid Mechanics \& Thermal Sciences, Vol. 1, No. 3, pp. 72-82. DOI: 10.11648/j.ijfmts.20150103.15

[4] Aminossadati S.M., Ghasemi B. (2005). The effects of orientation of an inclined enclosure on laminar natural convection, International Journal of Heat and Technology, Vol. 23, No. 2, pp. 43-49.

[5] Abu-Nada E., Oztop H.F. (2009). Effects of inclination angle on natural convection in enclosures filled with $\mathrm{Cu}$-water nanofluid, International Journal of Heat and Fluid Flow, Vol. 30, No. 4, pp. 669-678. DOI: https://doi.org/10.1016/j.ijheatfluidflow.2009.02. $\underline{001}$

[6] Oztop H.F., Al-Salem K., VarolY., Pop I., Firat M. (2012). Effects of inclination angle on natural convection in inclined open porous cavity with nonisothermally heated wall, International Journal of Numerical Methods for Heat and Fluid Flow, Vol. 22, No. 8, pp. 1053-1072. DOI: https://doi.org/10.1108/09615531211271862

[7] Kherief M.N., Talbi K., Berrahil F. (2012). Effects of inclination and magnetic field on natural convection flow induced by a vertical temperature, Journal of Applied Fluid Mechanics, Vol. 5, No. 1, pp. 113-120.

[8] Hussein A.K., Ahmed S.A., Saha S., Hasanpour A., Mohammed H.A., Kolsi L., Adegun I.K. (2012). MHD natural convection inside an inclined trapezoidal porous enclosure with internal heat generation or absorption subjected to isoflux heating, 
Heat Transfer-Asian Research, Vol. 41, No. 6, pp. 498-515. DOI: $10.1002 / \mathrm{htj} .21013$

[9] Mamou M., Hasnaoui M., Vasseur P., Bilgen E. (1994). Natural convection heat transfer in inclined enclosures with multiple conducting solid partitions, Numerical Heat Transfer Part A, Vol. 25, pp. 295315. DOI: $10.1080 / 10407789408955950$

[10] Hussain A., Al-Makhyoul Z.M., Al-Aboshi R.I. (2013). Effect of vertical partition on natural convection flow in enclosure with adjacent inclined single wall, Journal of Engineering and Development, Vol. 17, No. 3, pp. 1813- 7822.

[11] Ben-Nakhi A., Chamkha A.J. (2006). Natural convection in inclined partitioned enclosures, Heat and Mass Transfer, Vol. 42, pp. 311-321. DOI 10.1007/s00231-005-0014-5

[12] Al-Rashed A., Kolsi L., Kalidasan K., Malekshah E.H., Borjini M.N., Kanna P.R. (2017), Second law analysis of natural convection in a CNT-Water Nanofluid filled inclined 3D Cavity with incorporated Ahmed Body, International Journal of Mechanical Sciences, Vol. 130, pp. 399-415. DOI: http://dx.doi.org/10.1016/j.ijmecsci.2017.06.028

[13] Al-Rashed A., Kolsi L., Hussein A.K., Hassen W., Aichouni M., Borjini M.N. (2017), Numerical study of three-dimensional natural convection and entropy generation in a cubical cavity with partially active vertical walls, Case Studies in Thermal Engineering, Vol. $10, \quad$ pp. $100-110 . \quad$ DOI: https://doi.org/10.1016/j.csite.2017.05.003

[14] Al-Rashed A., Kolsi L., Kalidasan K., Maatki C., Borjini M.N., Aichouni M., Kanna P.R. (2017), Effect of magnetic field inclination on magneto-convective Induced irreversibilities in a CNT-water nanofluid filled cubic cavity, Frontiers in Heat and Mass Transfer, Vol. 8, No. 31. DOI: 10.5098/hmt.8.31

[15] Al-Rashed A., Aich W., Kolsi L., Mahian O., Hussein A.K., Borjini M.N. (2017). Effects of movable-baffle on heat transfer and entropy generation in a cavity saturated by CNT suspensions: Three dimensional modelling, Entropy, Vol. 19, p. 200. DOI: $\underline{10.3390 / \mathrm{e} 19050200}$

[16] Oztop H.F., Kolsi L., Alghamdi A., Abu-Hamdeh N., Borjini M.N., Aissia H.B. (2017). Numerical analysis of entropy generation due to natural convection in three-dimensional partially open enclosures, Journal of the Taiwan Institute of Chemical Engineers, Vol. $75, \quad$ pp. $131-140 . \quad$ DOI: org/10.1016/j.jtice.2017.03.014

[17] Kolsi L., Oztop H.F., Abu-Hamdeh N., Borjini M.N., Aissia B.H. (2017). Effects of moving lid direction on mixed convection and entropy generation in a cubical cavity with longitudinal triangular fin insertion, International Journal of Numerical Methods for Heat \& Fluid Flow, Vol. 27, No. 4, pp. 839-860. DOI: https://doi.org/10.1108/HFF-02-2016-0054

[18] Kolsi L., Lajnef E., Aich W., Alghamdi A., Aichouni M., Borjini M.N., Aissia H.B. (2017). Numerical investigation of combined buoyancy-thermocapillary convection and entropy generation in 3D cavity filled with $\mathrm{Al}_{2} \mathrm{O}_{3}$ nanofluid, Alexandria Engineering Journal, Vol. 56, pp. 71-79. DOI: https://doi.org/10.1016/j.aej.2016.09.005

[19] Al-Rashed A., Kolsi L., Oztop H.F., Abu-Hamdeh N., Borjini M.N. (2017). Natural convection and entropy production in a cubic cavity heated via pin-fins heat sinks, International Journal of Heat and Technology, Vol. 35, No. 1, pp. 109-115. DOI: 10.18280/ijht.350115

[20] Kolsi L., Oztop H.F., Alghamdi A., Abu-Hamdeh N., Borjini M.N., Ben Aissia H. (2016). A computational work on three-dimensional analysis of natural convection and entropy generation in nanofluid filled enclosures with triangular solid insert at the corners, Journal of Molecular Liquids, Vol. 218, pp. 260-274. DOI: $\underline{10.1016 / j . m o l l i q .2016 .02 .083}$

[21] Kolsi L., Mahian O., Oztop H.F., Aich W., Borjini M.N., Abu-Hamdeh N., Aissia H.B. (2016). 3D Buoyancy induced flow and entropy generation of nanofluid filled open cavity having adiabatic diamond shaped obstacle, Entropy, Vol. 18, No. 6, p. 232. DOI: 10.3390/e18060232

[22] Kolsi L., Kalidasan K., Alghamdi A., Borjini M.N., Kanna P.R. (2016). Natural convection and entropy generation on a cubical cavity with twin adiabatic blocks and filled by aluminium oxide-water nanofluid, Numerical Heat Transfer Part A, Vol. 70, No. 3, pp. 242-259. DOI: $\underline{10.1080 / 10407782.2016 .1173478}$

[23] Kolsi L., Abu-Hamdeh N., Oztop H., Alghamdi A., Borjini M.N., Aissia H.B. (2016). Natural convection and entropy generation in a three dimensional volumetrically heated and partially divided cavity, International Journal of Numerical Methods for Heat \& Fluid Flow, Vol. 26, No. 8, pp. 2492-2508. DOI: 10.1108/HFF-09-2015-0358.

[24] Kolsi L. (2016). Numerical study of natural convection and entropy generation of $\mathrm{Al}_{2} \mathrm{O}_{3}$-water nanofluid within a cavity equipped with a conductive baffle, Journal of Applied Fluid Mechanics, Vol. 9, No. 5, pp. 2177-2186.

[25] Kolsi L., Oztop H.F., Abu-Hamdeh N., Alghamdi A., Borjini M.N. (2016). Three-dimensional analysis of natural convection and entropy generation in a sharp edged finned cavity, Alexandria Engineering Journal, Vol. 55, pp. 991-1004. DOI: 10.1016/j.aej.2016.02.030

[26] Kolsi L. (2016). MHD mixed convection and entropy generation in a 3D lid-driven cavity, Frontiers in Heat and Mass Transfer, Vol. 7, No. 26. DOI: 10.5098/hmt.7.26

[27] Kolsi L., Hussein A.K., Borjini M.N., Mohammed H.A., Aïssia H.B. (2014), Computational analysis of three-dimensional unsteady natural convection and entropy generation in a cubical enclosure filled with water- $\mathrm{Al}_{2} \mathrm{O}_{3}$ nanofluid, Arabian Journal for Science and Engineering. Vol. 39, pp. 7483-7493. DOI: 10.1007/s13369-014-1341-y

[28] Bouabid M., Brahim A.B. (2011). Entropy generation study of MHD thermosolutal convection in a square cavity for different prandtl numbers, International Journal of Mechanics And Applications, Vol. 1, No. 1, pp. 22-29. DOI: 10. 5923/j.mechanics.20110101.03

[29] Baytas A.C. (2000). Entropy generation for natural convection in an inclined porous cavity, Int. J. Heat Mass Transfer, Vol. 43, pp. 2089-2099. DOI: 10.1016/s0017-9310(99)00291-4

[30] Shavik S.M., Nassim M., Hassan A.K., Morshed M., Islam M.Q. (2014). Natural convection and Entropy generation in squares inclined cavity with differentially heated vertical walls, Procedia 
Engineering, Vol. 90, pp. 557 - 562. DOI: 10.1016/j.proeng.2014.11.772

[31] Bouabid M., Hidouri M., Magherbi N.M., Brahim A.B. (2011). Analysis of the magnetic field effect on entropy generation at thermosolutal convection in a square cavity, Entropy, Vol. 13, pp. 1034-1054. DOI: 10.3390/e13051034

[32] Amraqui S., Mezrhab A., Abid C. (2011). Combined natural convection and surface radiation in solar collector equipped with partitions, Applied Solar Energy, Vol. 47, No. 1, pp. 36-47. DOI: 10.3103/s0003701x11010051

[33] Heidary H., Kermani M.J. Pirmohammadi M. (2016). Partition effect on thermo magnetic natural convection and entropy generation in inclined porous cavity, Journal of Applied Fluid Mechanics, Vol. 9, No. 1, pp. 119-130.

\section{NOMENCLATURE}

d distance between partitions [-]

D thermal diffusivity $\left[\mathrm{m}^{2} \cdot \mathrm{s}^{-1}\right]$

e partitions thickness [-]

g acceleration due to gravity $\left[\mathrm{m} \cdot \mathrm{s}^{-2}\right]$

$\mathrm{k}$ Thermal conductivity $\left[\mathrm{W} \cdot \mathrm{m}^{-1} \cdot \mathrm{K}^{-1}\right]$

$\mathrm{L}$ characteristic length [m]

$\mathrm{Nu}$ Nusselt number [-]

$\mathrm{P}$ pressure [N.m $\left.{ }^{-2}\right]$

Pr Prandtl number $(=v / D)[-]$

$\vec{q} \quad$ heat flux vector

Ra Rayleigh number $=\left(g \beta_{T}\left(T_{h}-T_{c}\right) L^{3} / v D\right)$ [-]

$\mathrm{R}_{\mathrm{c}} \quad$ Thermal conductivity ratio [-]

$\mathrm{S}$ generated entropy $\left[\mathrm{KJ} \cdot \mathrm{Kg}^{-1} \cdot \mathrm{K}^{-1}\right.$ ]

$\mathrm{t}$ time [s]
T temperature [-]

$\mathrm{V}$ dimensionless velocity vector [-]

$\mathrm{u}, \mathrm{v}, \mathrm{w}$

velocity components in $\mathrm{x}, \mathrm{y}, \mathrm{z}$ directions $\left[\mathrm{m} . \mathrm{s}^{-1}\right]$

\section{Subscripts}

C cold

f fluid

fr friction, viscous

gen generated

h hot

$\mathrm{m}$ average

$n$ the direction of $n$ is normal to a given wall

$\mathrm{p}$ solid

th thermal

tot total

$\mathrm{x}, \mathrm{y}, \mathrm{z}$ Cartesian coordinates

$0 \quad$ Reference

\section{Greek Symbols}

$\alpha \quad$ inclination angle of the cavity $\left[{ }^{\circ}\right]$

$\beta t \quad$ thermal bulk expansion coefficient $\left[\mathrm{K}^{-1}\right]$

$\Delta T$ temperature difference [K]

$\mu \quad$ dynamic viscosity, $\left[\mathrm{kgm}^{-1} \mathrm{~s}^{-1}\right]$

$v \quad$ kinematic viscosity $\left[\mathrm{m}^{2} \cdot \mathrm{s}^{-1}\right]$

$\rho \quad$ fluid density $\left[\mathrm{kg} \cdot \mathrm{m}^{-3}\right]$

$\phi$ the irreversibility distribution coefficient ratio

$\psi \quad$ vector potential

$\omega$ vorticity

\section{Superscript}

'dimensional variable 